\title{
Modeling and Validation of Passive Rectifier for Airplanes with Variable Frequency and Bipolar DC Buses
}

\author{
Lais Abrantes Vitoi ${ }^{1}{ }^{*}$ (D), Jose Antenor Pomilio² [D, Danilo Iglesias Brandão ${ }^{1}$ (D)
}

1.Universidade Federal de Minas Gerais - Escola de Engenharia - Departamento de Engenharia Elétrica - Belo Horizonte/MG Brazil. 2. Universidade Estadual de Campinas - Faculdade de Engenharia Elétrica e de Computação - Campinas/SP - Brazil.

*Corresponding author: laisvitoi@gmail.com

\begin{abstract}
Traditional airplanes with fixed frequency and unipolar DC bus (270 V) commonly use 12-pulse passive rectifiers. The increase of power demand and the concern with aircraft efficiency boost the electrification of airplanes using variable frequency $(360-800 \mathrm{~Hz})$ and bipolar DC buses $( \pm 270 \mathrm{~V})$. Thus, this paper analyses the 12-pulse passive rectifiers in this new scenario. It is proposed an accurate model, describing its design, to verify if passive rectifiers are suitable for aircraft application complying with current standards. The analysis of the 12-pulse rectifier is done by an association of two 6-pulse rectifiers and considering both sorts of an input filter, L and LC. The mathematical model is presented and considers typical harmonic components, allowing precise analysis of input current and output voltage. Simulation and experimental results are provided to validate the mathematical model. The paper shows that the 12-pulse passive rectifier is not a viable solution when operating under variable frequency, which was verified by the violation of the electricity quality standards.
\end{abstract}

Keywords: Bipolar DC buses; More electric aircraft; Variable frequency systems; 12-pulse rectifier.

\section{INTRODUCTION}

The search for more energy efficient solutions is a technological trend in all application fields. Usually, the road map includes the replacement of mechanical, hydraulic and pneumatic systems for electrical solutions (Rosero et al., 2007). In the aeronautic case, such movement is called "More Electric Aircraft" (MEA). Reduction of fuel consumption and environmental impact can be highlighted as the main reasons for this transition. But MEA also reduces maintenance costs, weight, noise and improves the overall efficiency and reliability of the aircraft (Cao et al. 2012; Chen et al. 2016; Emadi and Ehsani 2000; Rosero et al. 2007; Sarlioglu and Morris 2015; Wheeler and Bozhko 2014).

Traditionally, aeronautical systems operate with a three-phase $115 \mathrm{~V}$ line-to-neutral AC voltage at constant frequency of $400 \mathrm{~Hz}$ (Rosero et al. 2007; Sarlioglu and Morris 2015). The Constant Frequency Integrated Drive Generator (IDG) mechanically changes the variable turbine speed to a constant speed. In the MEA context, the modern aircrafts are eliminating the IDG by connecting the generator directly to the engine, which results in a Variable Frequency Generation (VFG) system. The AC frequency varies in a range of $360-800 \mathrm{~Hz}$.

Received: Mar. 18, 2020 | Accepted: Oct. 20, 2020

Peer Review History: Double Blind Peer Review

Section Editor: Alison Moraes

This is an open access article distributed under the terms of the Creative Commons license. 
The airplane DC voltage level is conventionally $28 \mathrm{~V}$. Due to the growth in electricity demand, another DC bus of $270 \mathrm{~V}$ has been created to feed the higher power devices. By increasing the voltage, it is possible to reduce the current and consequently the weight of the cables while maintaining the same amount of power. As power demand continues to increase, such DC bus has doubled to $\pm 270 \mathrm{~V}$, making it possible to supply loads of 270 and $540 \mathrm{~V}$ (Buticchi et al. 2017; Chen et al. 2016; Jia and Rajashekara 2017a; Rosero et al. 2007; Sarlioglu and Morris 2015; Wheeler and Bozhko 2014).

This paper discusses the use of passive rectifiers that connect the AC variable frequency source to the $\pm 270 \mathrm{~V}$ bipolar DC bus. The behavior evaluation is based on the avionic standards MIL-STD-704F (USA 2008), which provides the aircraft electric power characteristics, and RTCA DO-160F (USA 2007), which provides the aircraft the environmental conditions and test procedures for airborne equipment.

The main items of MIL-STD-704F are summarized in Table 1 and the harmonic current limits for balanced three phase electrical equipment can be found in the standard RTCA-DO-160E (USA 2007). From the AC perspective, the rectifier is seen as a load and it must comply with the specifications of RTCA DO-160F. In turn, from the load perspective, the rectifier is considered as a source and must comply with the requirements of MIL-STD-704F. Nonetheless, there are no published aircraft standards for the power quality of this voltage level $(540 \pm 270 \mathrm{~V})$, thus the analysis and results are compared with the limits of MIL-STD-704F for 270 V.

Table 1. AC and DC normal operation characteristics (USA 2008).

\begin{tabular}{cc}
\hline \multicolumn{2}{c}{ AC BUS } \\
\hline Frequency $(f)$ & 360 to $800 \mathrm{~Hz}$ \\
\hline RMS steady state voltage - phase voltage $\left(V_{s_{\varphi}}\right)$ & 108 to $118 \mathrm{~V}$ \\
\hline $270 \mathrm{~V}$ DC BUS & 250 to $280 \mathrm{~V}$ \\
\hline Steady state voltage - average value $\left[\bar{V}_{o}\right)$ & $6.0 \mathrm{~V}$ maximum \\
\hline Ripple amplitude - peak to mean $\left(\Delta v_{o}\right)$ &
\end{tabular}

The 12-pulse rectifier is widely used in aeronautical systems operating at fixed frequency (Gong et al. 2003; 2004; Xu et al. 2017), once it is simple, robust and the low order harmonics are canceled (Vitoi et al. 2017a) (Jiang et al. 2012). However, with the system operating at variable frequency, the vast majority of academic papers propose solutions using active circuits (Buticchi et al. 2017; Hartmann et al. 2012; Jia and Rajashekara 2017a,b; Taha 2018; Yin et al. 2017). The active circuits are a good solution in terms of limiting the harmonic content for a system with variable frequency but, once it is controlled, it adds more complexity to the system, maintenance and financial costs.

There are few papers analyzing the 12-pulse non-controlled rectifier operating in variable frequency (Gong et al. 2003; 2004; 2005; Mino et al. 2005). These papers consider the variable frequency system and work with rated power of $5 \mathrm{~kW}$ to $10 \mathrm{~kW}$. Gong et al. $(2003 ; 2004 ; 2005)$ consider the 12-pulse rectifier as an association of two 6-pulse rectifiers connected in parallel providing only one level of DC voltage and utilize an input inductor to limit the harmonic currents. In Gong et al. (2005), the output power limitation and the main current quality are analyzed in detail. None of those papers have performed the analysis of an LC input filter and a bipolar output voltage.

This study is aimed at analyzing the 12-pulse rectifier that is commonly used in traditional aeronautical systems. The problem statement is to verify if the 12-pulse passive rectifier is suitable for aircraft applications with variable frequency and bipolar DC voltage complying with the current standards. The paper evaluates whether the rectifier meets the standard limits for normal operating conditions, specifically the limits of input harmonic currents and DC voltage. It is firstly considered the circuit under an ideal condition, i.e., no losses, balanced loads, ideal components and the transformer with no imbalance. Thus, if the converter meets the standard requirements under the ideal condition, a second stage analysis must be performed considering the typical real conditions (losses, asymmetries, unbalance, among many others). On the other hand, if the rectifier under ideal condition does not comply with required standards, then it is not suitable for aircraft applications. 
Finally, this work is an extended version of Vitoi et al. (2017b) and performs a complete analysis of the 12-pulse rectifier applied to aircraft systems. A complete mathematical model of the rectifier with two filter types (L and LC) is developed. Differently from Vitoi et al. (2017b), this study analyzes in detail the mathematical model and gives a deeper analysis on the experimental results. It also emphasizes a description of the state of the art and presents further simulation and experimental results.

\section{2-PULSE UNCONTROLLED RECTIFIER}

The 12-pulse rectifier circuit is shown in Fig. 1. It consists of a transformer with Y-primary and two secondaries (Y and Delta), each secondary is connected to a 6-pulse rectifier. When supplying balanced load, an effective cancellation of the 5th and 7th harmonics occur and the input current only shows odd harmonic components multiple of the pulse number, i.e., $h=11,13,23$, 25... The 12-pulse rectifier configuration allows an implementation of symmetric buses without the need for an additional circuit. The rectifiers outputs are connected in series to generate the bipolar DC buses $( \pm 270 \mathrm{~V})$.

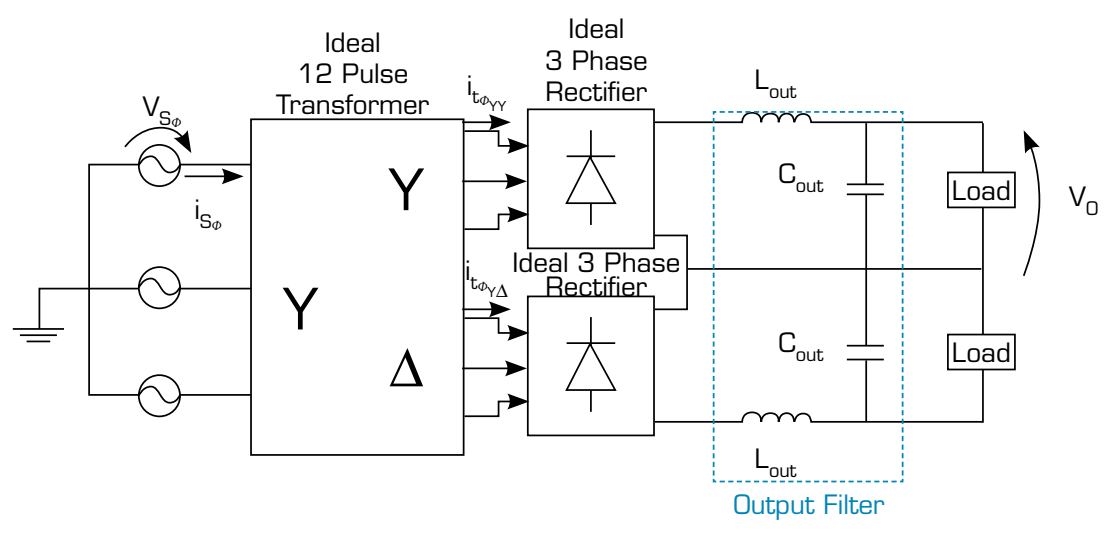

Figure 1. Schematic of 12-pulse rectifier with LC DC filter.

Once the loads are considered balanced, the results in both rectifiers and DC buses are equal, therefore, the analysis is done for each rectifier independently and then combined to generate the solution for the 12-pulse rectifier. In addition, the results in the DC bus are shown only for one of the rectifiers because the loads are considered balanced. The analysis is performed for an aeronautical system of $50 \mathrm{~kW}$ ( $25 \mathrm{~kW}$ for each rectifier), which is compatible with medium size aircraft (Jia and Rajashekara 2017a). However, the entire mathematical model is valid for any range of power. The loads are modeled as constant power, once the DC loads are predominantly controlled electronic.

An LC output filter is used to minimize the load voltage ripple to accomplish the standard limits, as shown in Table 1. The filter was sized considering the ripple at the output voltage, $V_{o}$, the capacity of conduction of the capacitor and the cutoff frequency tuned at $500 \mathrm{~Hz}$ in order to operate with an adequate margin regarding the ripple limit, once the minimum frequency on the DC side is six times $360 \mathrm{~Hz}$. Therefore, the following values were found: $L_{\text {out }}=500 \mu \mathrm{H}$ and $C_{\text {out }}=200 \mu \mathrm{F}$. This filter value will be used in the model and simulation analysis with L and LC input filters. Further details of the output filter design can be found in Vitoi (2018).

Figure 2 shows the load voltage and Fig. 3 shows the voltage, $v_{s} \Phi$, and current, $i_{s} \Phi$, at the source, respectively. The harmonic spectrum of source current is shown in Fig. 4. Using the DC filter, the output voltage ripple limit is respected; however, the high order harmonics of the input current are still above the standard limits, as shown in Fig. 4 . Thus, it is not possible to meet aeronautical standards using only a DC filter. Therefore, the use of passive AC filters is analyzed considering L and LC filters. 


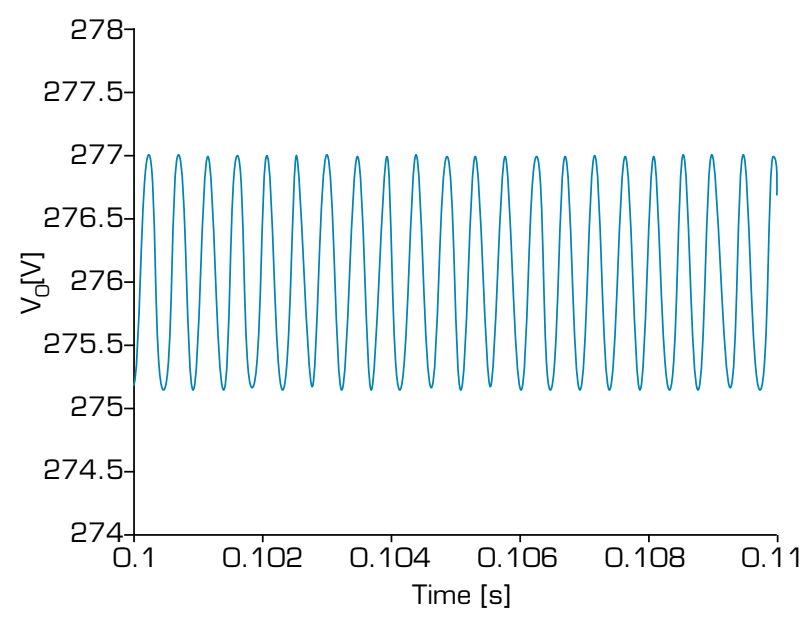

Figure 2. Output voltage with an LC DC filter $-V_{s \Phi}=118 \mathrm{~V}$ and $f=360 \mathrm{~Hz}$.

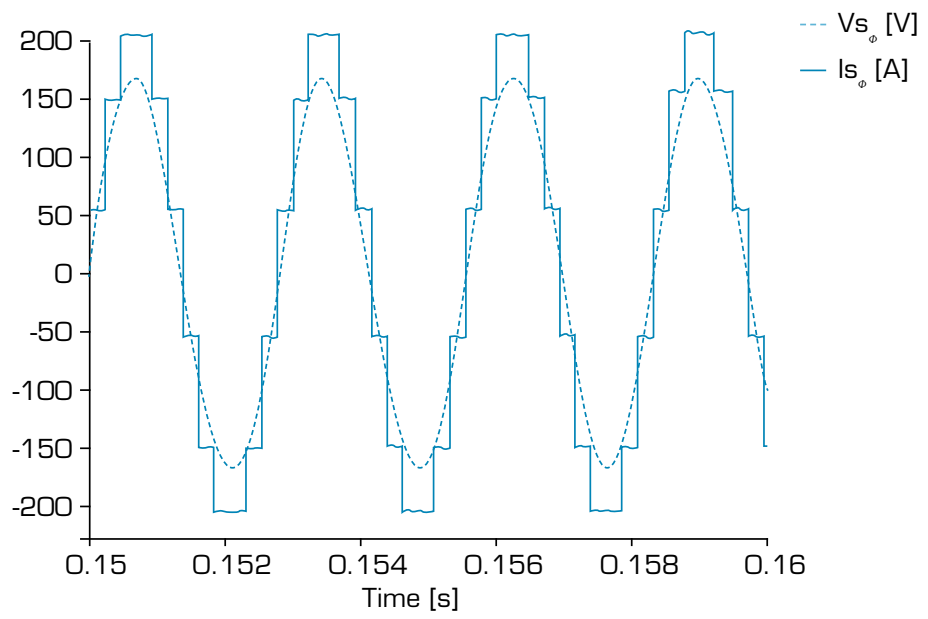

Figure 3. Input voltage and current with an LC DC filter $-V_{s_{\oplus}}=118 \mathrm{~V}$ and $f=360 \mathrm{~Hz}$.

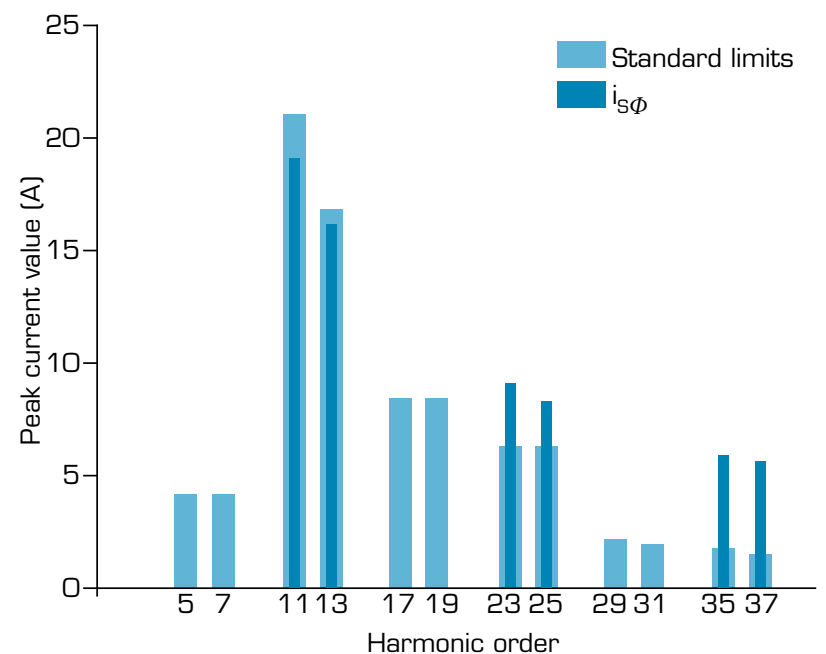

Figure 4. Harmonic content of the input current with LC DC filter $-V_{s \Phi}=118 \mathrm{~V}$ and $f=360 \mathrm{~Hz}$. 


\section{MATHEMATICAL MODEL}

\section{First order input $L$ filter}

The simplest AC filter uses only an input inductor $\left(L_{i n_{0}}\right)$, as shown in Fig. 5. Source and transformer inductances are included in $L_{i{ }_{\infty}}$ value. This filter limits the AC harmonic currents but the inductor, in series with the source, produces a notch effect in which two diodes of the same half bridge conduct simultaneously, causes notches on the rectifier input voltage and drops the DC voltage, as can be seen in Fig. 6 (Rashid 2009).

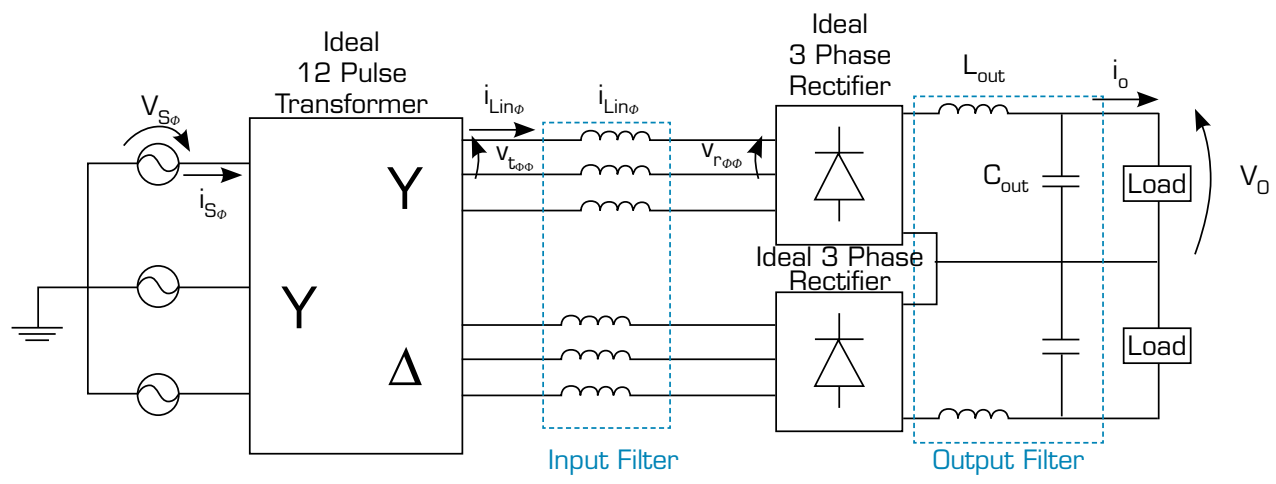

Figure 5. Circuit using the input L filter.
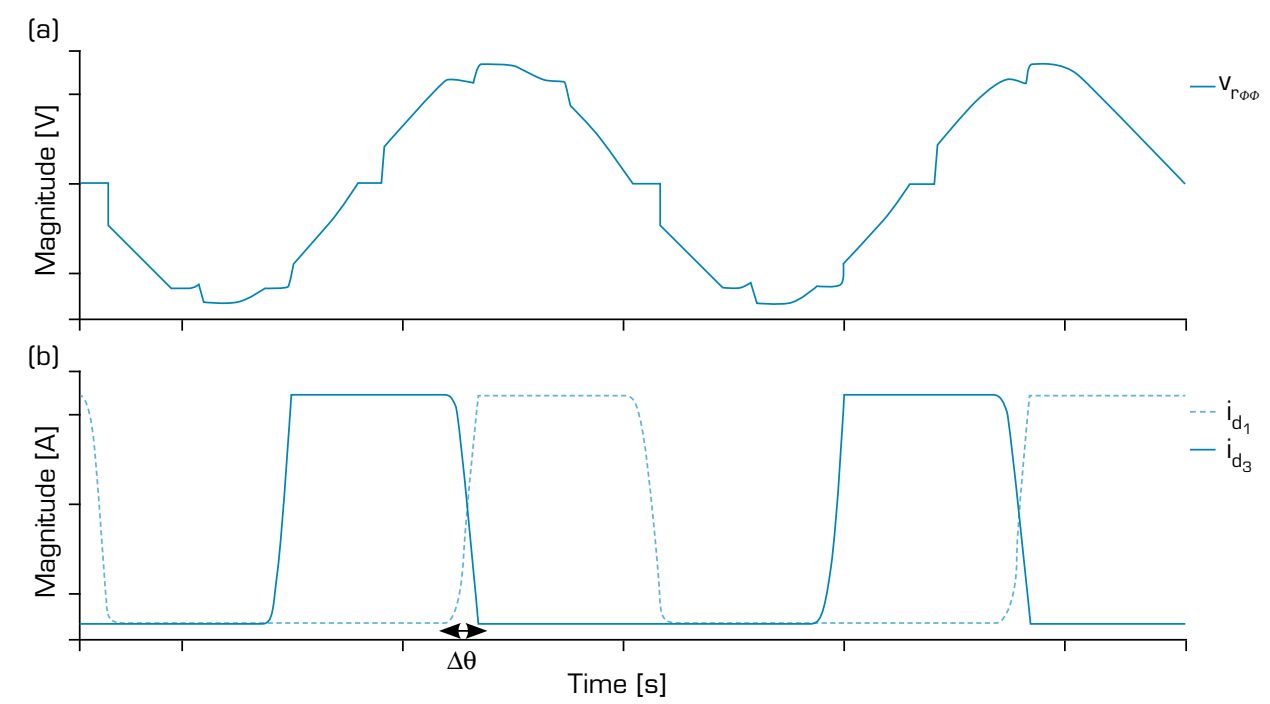

Figure 6. Notch effect: rectifier input voltage (a) and current in the diodes of the same half bridge (b).

Thus, there is a maximum value of $L_{i n \Phi}$ so that the average output voltage $\left(\overline{V_{o}}\right)$ is still within the standard limits $\left(\overline{V_{\text {min }}}=250 \mathrm{~V}\right)$. The notch effect is already widely studied in the literature (Rashid 2009) and Eq. 1 models the system to find the maximum value allowed of the input inductor $\left(L_{\text {inoma }}\right)$. Since this equation models the average output voltage value, the DC output filter does not interfere with the value of $L_{\text {in } \Phi_{\text {max }}}$. It is considered that the rectifier operates in continuous mode and the input current varies approximately linearly during the commutation interval. $N$ is the voltage ratio of the transformer and $P_{3 \Phi}$ is the total active power at one branch of the circuit.

$$
\overline{V_{o_{\min }}}-\frac{3 \sqrt{6}}{\pi} V_{s_{\phi}} N+6 f L_{i n_{\phi_{\max }}} \frac{P_{3 \phi}}{\overline{V_{o_{\min }}}}=0
$$


$L_{i n \diamond}$ must also limit the harmonics of the input current, thus there is a minimum inductance value $\left(L_{\text {inomin }}\right)$ to satisfy the standard limits. To model this situation, the rectifier input voltage shown in Fig. 6 is analyzed. In commutation intervals $\left(\theta_{x}=0, \pi / 3,2 \pi / 3, \pi\right.$, $4 \pi / 3$ and $5 \pi / 3 \mathrm{rad})$, the rectifier input line voltage $\left(v_{r_{\phi}}\right)$ remains approximately constant, thus $v_{r_{\infty}}$ function can be written as Eq. 2 .

$$
v_{r_{\phi \phi}}(\theta)=v_{s_{\phi \phi}}(\theta) N-u_{\phi \phi}(\theta)
$$

where $u_{\Phi \Phi}$ is defined as Eq. 3 and $\theta$ is the angle in radians. Figure 7 shows the graph of $u_{\Phi \Phi}$ function.

$$
u_{\phi \phi}(\theta)= \begin{cases}N\left(v_{s_{\phi \phi}}(\theta)-v_{s_{\phi \phi}}\left(\theta_{x}\right)\right), & \text { if } \theta_{x} \leq \theta \leq \theta_{x}+\Delta \theta \\ 0, & \text { otherwise }\end{cases}
$$

where $\Delta \theta$ is the duration of the commutation in radians (Fig. 6) and $v_{s \oplus \infty}(\theta)$ is the function of the source line voltage.

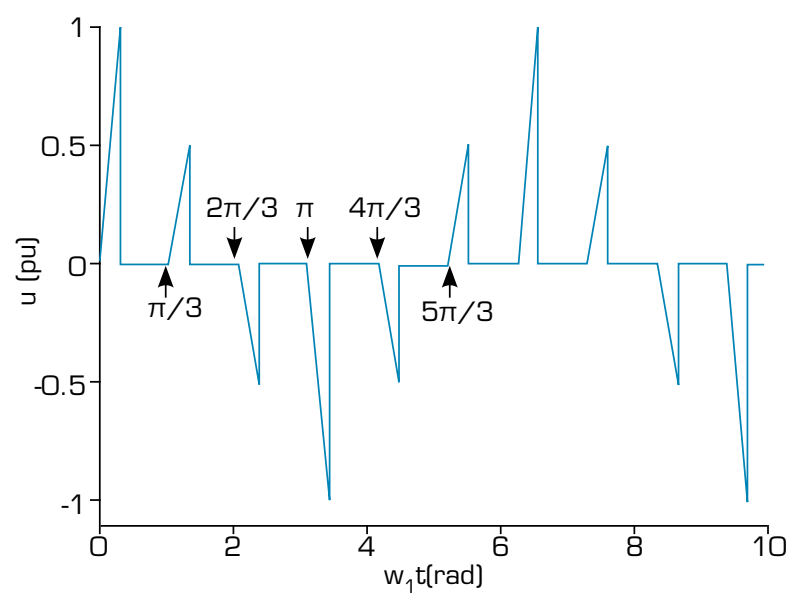

Figure 7. Graph of $u_{\Phi \Phi}$ function.

As $v_{s \Phi \Phi}(\theta)$ is a pure sine wave, the harmonic content of $v_{r \oplus \phi}(\theta)$ is entirely present in function $u_{\Phi \Phi}(\theta)$ (see Eq. 2). The sinusoidal voltage can be approximated by a straight line in each commutation point, $\theta_{x}$ (first order Taylor approximation). Therefore, $v_{s \triangleright \infty}(\theta)$ is written as Eq. 4.

$$
v_{s_{\phi \phi}}(\theta)=\alpha_{x}\left(\theta-\theta_{x}\right)+v_{s_{\phi \phi}}\left(\theta_{x}\right)
$$

where $\alpha_{x}$ is the derivative of function $v_{s \oplus \infty}(\theta)$ in the commutation points $\left(\theta_{x}\right)$. Substituting Eq. 4 for Eq. 3, it results in a simpler equation for $u_{\Phi \Phi}$.

$$
u_{\phi \phi}(\theta)= \begin{cases}N \alpha_{x}\left(\theta-\theta_{x}\right), & \text { if } \theta_{x} \leq \theta \leq \theta_{x}+\Delta \theta \\ 0, & \text { otherwise }\end{cases}
$$

Eq. 6 is the Fourier series of $u_{\Phi \Phi}(\theta)$. 


$$
u_{\phi \phi}(\theta)=A_{0}+\sum_{n=1}^{\infty} A_{n} \cos (n \theta)+\sum_{n=1}^{\infty} B_{n} \sin (n \theta)
$$

The coefficients are functions of $\Delta \theta$. In order to calculate the values, some considerations are made:

- The input current $\left(i_{\text {Lino }}(\theta)\right)$ varies linearly during the commutation interval, as shown in Fig. 6. $v_{\text {Lino }}(\theta)$ is the voltage function over $L_{i n \sigma^{\prime}}$ and $V_{\text {Lino }}$ is its RMS value. $\Delta t$ is the duration of the commutation in seconds and $\bar{I}_{o}$ is the average output current.

$$
\begin{gathered}
v_{L_{i n_{\phi}}}(\theta)=L_{i n_{\phi}} \frac{\partial i_{L_{i n_{\phi}}}(\theta)}{\partial t}=L_{i n_{\phi}} \frac{\Delta i_{L_{i n_{\phi}}}(\theta)}{\Delta t} \\
V_{L_{i n_{\phi}}}=L_{i n_{\phi}} \overline{I_{o}} / \Delta t
\end{gathered}
$$

- As evidenced in Eq. 9, the left side of the equation is sinusoidal and the right side of the equation is linear. This is valid just at the commutation instants, where the sinusoidal line voltage at the transformer output $\left(v_{\text {too }}(\theta)\right)$ is approximated by a straight line. As the duration of the commutation is the same for all $\theta_{x^{\prime}}$, the calculation is done at $\theta_{x}=0$ rad. $V_{\text {too-peak }}$ is the peak value of $v_{\text {too }}(\theta)$.

$$
v_{t_{\phi \phi}}(\theta)=V_{t_{\phi \phi-p e a k}} \theta
$$

- The voltages across the inductors involved in the commutation are equal, approximately constant and assume the instantaneous value of $v_{t o o} / 2$ at half of the commutation interval. Using Eq. 9, Eq. 10 is found, where $\omega$ is the supply angular frequency.

$$
V_{L_{i n_{\phi}}}=\frac{v_{t_{\phi \phi}}(\Delta t / 2)}{2}=\frac{V_{t_{\phi \phi-p e a k}} \omega \Delta t}{4}
$$

Substituting Eq. 10 for Eq. 8, the commutation duration is:

$$
\Delta t=\sqrt{\frac{4 L_{i n_{\phi}} \overline{I_{o}}}{V_{t_{\phi \phi-p e a k}} \omega}}
$$

Thereby, it is possible to find the harmonic components of $u_{\Phi \Phi}(\theta)$, Eq. 6 .

Once $u_{\Phi \Phi}(\theta)$ is decomposed into the Fourier series, it is possible to analyze the phase circuit for each frequency. The variables are the phase RMS values for each harmonic (h). Thus, the inductor voltage drop is directly determined by $U_{\Phi \Phi-h}$ value, as described in Eq. 12.

$$
I_{t_{\phi-h}}=\frac{U_{\phi \phi-h}}{\sqrt{3} h \omega L_{i n_{\phi}}}
$$

For balanced loads, the input current in the 12-pulse transformer is zero for even harmonics and for multiples of three. For odd components, it is twice the value at the secondary windings, Eq. 12. Therefore, it is possible to find a minimum value of $L_{\text {in }}$ that complies with the standard limits. To facilitate the reader to implement and use this model, the mathematical model code implemented on Matlab software can be downloaded at: www.dsce.fee.unicamp.br/ antenor/model_Lin.zip. 
The transformer can be built with different voltage ratios, although there is a maximum value of $N$ in order to attain the output voltage $\left(\bar{V}_{o}\right)$ below $280 \mathrm{~V}$. It is possible to calculate this maximum value $\left(N_{\text {max }}\right)$ using Eq. 1 and adopting the worst conditions: $V_{s \Phi}=118 \mathrm{~V}, L_{i n_{\infty}}=0 \mathrm{H}$ and $\bar{V}_{o}=280 \mathrm{~V}$. Thus, Eq. 13 is found and the maximum value is $N_{\max }=1.0144$.

$$
\overline{V_{o}}=3 \sqrt{6} V_{s_{\phi}} N / \pi
$$

To evaluate the proposed mathematical model, it was implemented on Matlab and compared with the circuit simulation on

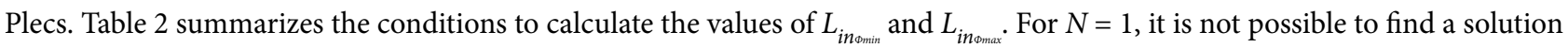
because, for all power range, $L_{\text {in } \phi_{\text {min }}}>L_{\text {in } \Phi_{\text {max }}}$. By changing the value of the transformer voltage ratio $(N=1.0144)$, the graph of $L_{\text {in }}$ as a function of the circuit power as shown in Fig. 8. For the rated power is found ( $25 \mathrm{~kW}$ for each rectifier), $L_{\text {inomin }}=12.36 \mu \mathrm{H}$ and $L_{\text {in } \oplus_{\max }}=13.05 \mu \mathrm{H}$.

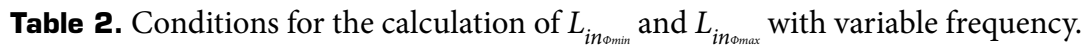

\begin{tabular}{cccc}
\hline \multirow{2}{*}{ Variable } & Symbol & \multicolumn{2}{c}{ Value } \\
\cline { 3 - 4 } & & $\boldsymbol{L}_{\boldsymbol{i n \Phi m i n}}$ & $\boldsymbol{L}_{\boldsymbol{i n}_{\Phi \max }}$ \\
\hline Supply rms phase voltage & $V_{s_{\odot}}$ & $118 \mathrm{~V}$ & $108 \mathrm{~V}$ \\
\hline Limiting condition & - & Harmonics of $I_{s}$ & $V_{o}=250 \mathrm{~V}$ \\
\hline Supply frequency & $f$ & $360 \mathrm{~Hz}$ & $800 \mathrm{~Hz}$ \\
\hline
\end{tabular}

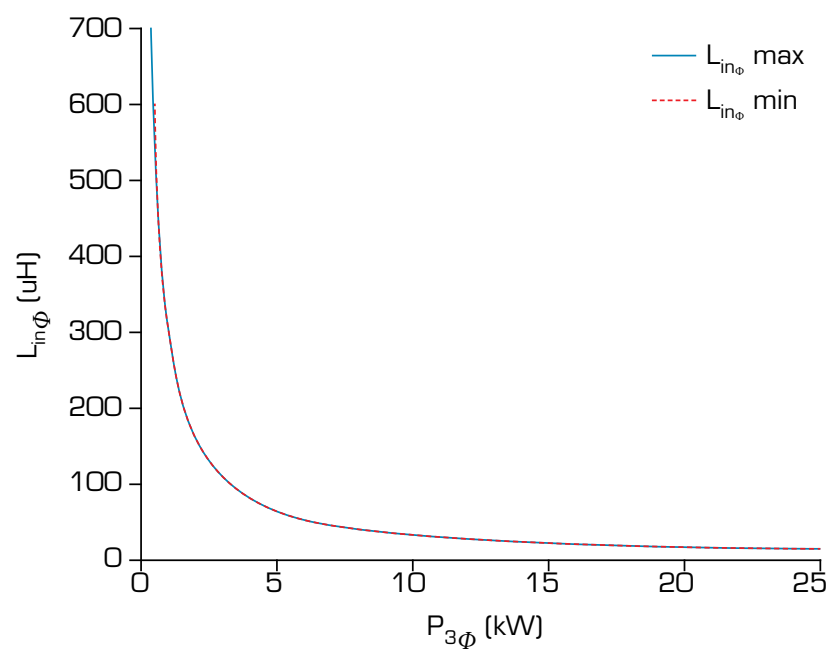

Figure 8. Maximum and minimum value of the input inductor for variable frequency with $\mathrm{N}=1.0144$.

Using $L_{i n \oplus}$ values found in the model, it is possible to analyze the circuit on a simulation software. Both are in agreement but, due to the paper size limitation, the simulation results are not shown in this paper and can be found on Vitoi (2018).

Although there is a numerical range of values for $L_{i n_{\odot}}$ between $L_{i n_{\text {min }}}$ and $L_{\text {inømax }}$, this value is too small to be used in a real situation, once the model is not considering losses, voltage drops in diodes, inductances of transformers, wires and generator (Baghramian et al. 2011; Chivite-Zabalza and Forsyth 2005; Cross et al. 2009; Gong et al. 2003; 2005; Mino et al. 2005). Therefore, it is necessary to explore other solutions to limit the harmonics of the input current.

\section{Second-order input LC filter}

A second-order LC may produce a more efficient filtering, minimizing the commutation interval and allowing the use of larger inductors, as shown in Fig. 9. For this analysis, all elements are considered ideal. 


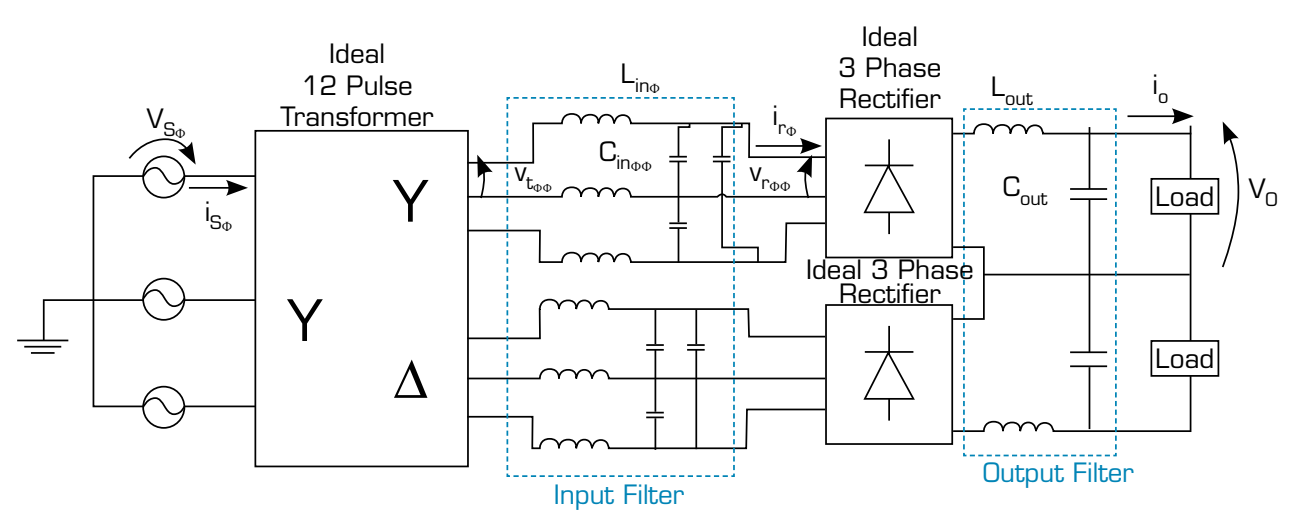

Figure 9. Circuit using the input LC filter.

For the LC filter, a different analysis is done. To model the circuit, the current at the input of the rectifier is analyzed ( $\left.i_{r_{0}}\right)$. Considering that the small oscillations in $i_{r_{\phi}}$ occur in harmonic frequencies, its fundamental is the same as the ideal curve, shown in Fig. 10. Therefore, using the term of the Fourier series first, the fundamental value $\left(i_{r_{\Phi-1}}(\theta)\right)$ is given by Eq. 14 and 15 .

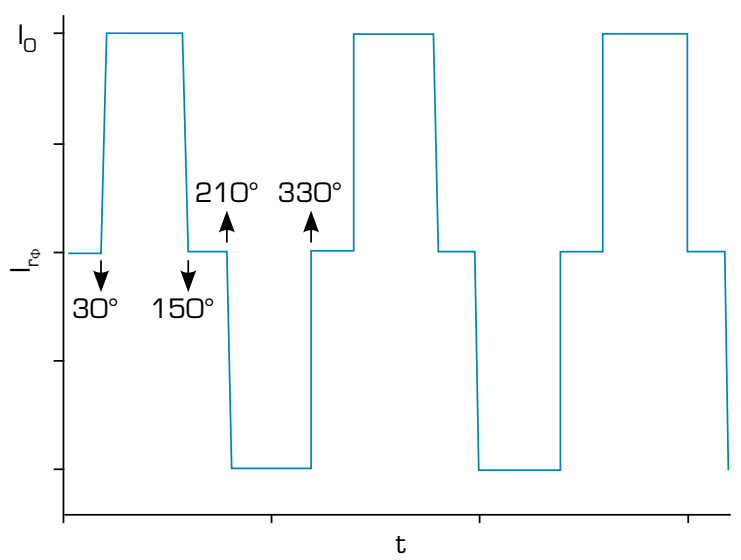

Figure 10. Ideal waveform to analyze the rectifier input current.

$$
i_{r_{\phi-1}}(\theta)=A_{1} \cos (\theta)+B_{1} \sin (\theta)
$$

where $A_{1}=0$ and $\mathrm{B} 1=2 \sqrt{3 \bar{I}_{0}} / \pi$. Therefore:

$$
i_{r_{\phi-1}}(\theta)=2 \sqrt{3} \overline{I_{o}} \sin (\theta) / \pi
$$

Since the source voltage is a pure sine wave, the total active power is entirely contained at the fundamental frequency of the source. Once the circuit is considered ideal, there are only reactive elements between the source and the rectifier, thus the active power at the rectifier input can be written as Eq. 16. $V_{r_{\phi-1}}$ is the RMS value of fundamental voltage at the rectifier input, $I_{r_{\phi-1}}$ is the RMS value of $i_{r_{\phi-1}}$ and $\varphi_{1}$ is the phase angle between $v_{r_{\phi-1}}$ and $i_{r_{\phi-1}}$. For the harmonics, the value of $\varphi$ is $90^{\circ}$, once a lossless circuit is being considered.

$$
P_{1 \phi}=V_{r_{\phi-1}} I_{r_{\phi-1}} \cos \left(\varphi_{1}\right)
$$

Moreover, $P_{1_{\Phi}}=P_{o} / 3$, in which $P_{o}$ is the active power drawn by one load. Thereby, using Eq. 15 and 16, there is a relation between $V_{r_{\phi-1}}$ and $\overline{V_{o}}$ : 


$$
\overline{V_{o}}=\frac{V_{r_{\phi-1}} \cos \left(\varphi_{1}\right) 6 \sqrt{3}}{\sqrt{2} \pi}
$$

The equivalent impedance seen by the input filter $\left(Z_{1}=V_{r_{0-1}} / I_{r_{0-1}}\right)$ has a resistive part, $R_{1}$, thus the active power can be written as (Eq. 18).

$$
P_{1 \phi}=R_{1} I_{r_{\phi-1}}^{2}
$$

Using Eq. 16, 17 and 18, a relation between $I_{r o-1}, \bar{V}_{o}$ and $R_{1}$ is found:

$$
I_{r_{\phi-1}}=\frac{\overline{V_{o}}}{R_{1}} \frac{\pi \sqrt{2}}{6 \sqrt{3}}
$$

Equating Eq. 15 and 19 and using $\overline{I_{o}}=P_{3_{\odot}} / \overline{V_{o}}$, a relation between $R_{1}$ and $\bar{V}_{o}$ is found:

$$
R_{1}={\overline{V_{o}}}^{2} \frac{\pi^{2}}{18 P_{3 \phi}}
$$

Thus, it is noticed that the output voltage can be found through $V_{r_{0-1}}$ and $\varphi_{1}$ (Eq. 17) or through $R_{1}$ (Eq. 20). The output voltage value depends on $V_{r-1}$, which depends on the values of the input filter $\left(L_{i n \infty}\right.$ and $\left.C_{i n o o}\right)$. Moreover, the harmonics of the input current also depend on the filter values.

The use of the LC filter after the transformer (secondary side) allows including the inductances of the transformer and generator in $L_{i n n^{\circ}}$. If the filter was used at the transformer primary side, its leakage inductance would affect the system behavior similarly to the L filter analysis. From the data presented in Baghramian et al. (2011), Chivite-Zabalza and Forsyth (2005), Cross et al. (2009), Gong et al. (2003; 2005), and Mino et al. (2005), the value of the total leakage inductance is around $300 \mu \mathrm{H}$ for a $50-\mathrm{kW}$ system.

To attenuate the harmonics of the input current, the filter resonance frequency should be lower than the lowest harmonic liable to exist in the circuit $\left(\mathrm{h}_{\min } \times \mathrm{f}_{\min }=5\right.$ th harmonic of $\left.360 \mathrm{~Hz}-1800 \mathrm{~Hz}\right)$, withal it must be greater than the maximum operating frequency $(800 \mathrm{~Hz})$. Thereby, $1200 \mathrm{~Hz}$ was chosen as the cutoff frequency of the filter. As the source voltage frequency can assume any value between 360 and $800 \mathrm{~Hz}$, if the resonance was tuned above $1800 \mathrm{~Hz}$, an operating frequency with a harmonic component at $1800 \mathrm{~Hz}$ would exist, which would probably lead the circuit to over voltage.

In order to calculate the relation between $L_{\text {ino }}$ and $C_{i n o o}$, the active power on the equivalent Thevenin circuit at fundamental frequency was analyzed. The values of Thevenin voltage $\left(V_{\text {tho-1 }}\right)$ and impedance $\left(X_{\text {tho-1 }}\right)$ are calculated by Eq. 21 and 22 , respectively (Rashid 2009). The subscript " 1 " indicates fundamental quantity, while $\omega_{r}$ is the cutoff angular frequency of the filter and $\omega$ is the angular frequency of the source.

$$
\begin{aligned}
V_{t h_{\phi-1}} & =V_{t_{\phi-1}} \frac{\omega_{r}^{2}}{\omega_{r}^{2}-\omega^{2}} \\
X_{t h_{\phi-1}} & =L_{i n_{\phi}} \frac{\omega_{r}^{2} w}{\omega_{r}^{2}-\omega^{2}}
\end{aligned}
$$

At first, the equivalent load is modeled as a resistance $\left(R_{1}\right)$, once the circuit without harmonics results in the current and voltage in phase at the rectifier input, even with some harmonic contents, this phase difference should not be large. Therefore, the active power can be calculated by Eq. 23 . 


$$
P_{1 \phi}=V_{r_{\phi-1}}^{2} / R_{1}
$$

The maximum power that can be delivered occurs when $R_{1}=X_{t h \phi_{-1}}$ (Rashid 2009), thus Eq. 24 can be written.

$$
P_{\max _{1 \phi}}=\frac{V_{r_{\phi-1}}^{2}}{\left|X_{t h_{\phi-1}}\right|}=\frac{\left|V_{t h_{\phi-1}}\right|^{2}}{2\left|X_{t h_{\phi-1}}\right|}
$$

Replacing the values of $V_{t h_{\Phi-1}}$ and $X_{t \phi_{\Phi-1}}$, the values of $L_{i n_{\Phi}}$ and $C_{i n_{\infty}}$ to supply the maximum power are found:

$$
\begin{gathered}
L_{i n_{\phi}}=\frac{\left(N V_{s_{\phi}}\right)^{2} \omega_{r}^{2}}{2 \omega P_{\max _{1 \phi}}}\left|\frac{1}{\omega_{r}^{2}-\omega^{2}}\right| \\
C_{i n_{\phi \phi}}=\frac{1}{3 L_{i n_{\phi}} \omega_{r}^{2}}
\end{gathered}
$$

The output power is limited by the value of $L_{i{ }_{\infty}}$ thus, it is possible to establish the maximum value of $L_{i{ }_{\infty}}$ with the worst operation conditions for this situation: minimum value of the source voltage and maximum frequency. Using these conditions and the cutoff frequency selected above, it is possible to find the values of $L_{i n \infty}$ and $C_{i n \infty \phi}$ using Eq. 25 and $26: L_{i n \infty}=250.6 \mu \mathrm{H}$ and $C_{i n \infty \phi}=23.39 \mu \mathrm{F}$. $L_{i n \Phi}$ value is close to the typical leakage inductances of the system, therefore, this value is feasible to be used. The capacitor value was found directly by Eq. 26, but it is not a commercial value.

To analyze the mathematical model, the circuit was simulated on the Plecs software with data of Table 3 ( $L_{i{ }_{\infty}}$ and $C_{i{ }_{\infty}}$ calculated above). The source current $\left(i_{s \Phi}\right)$ is analyzed only with $V_{s \Phi}=118 \mathrm{~V}$, since this configuration presents higher harmonic currents. Figure 11 shows the current spectra at the source $\left(I_{s \phi}\right)$ and at the output of the transformer $\left(I_{t \phi}\right)$. As evidenced, the harmonic limits of the source current are respected for both frequencies. With the circuit operating at $360 \mathrm{~Hz}$, the 5 th and $7 \mathrm{th}(1800 \mathrm{~Hz}$ and $2520 \mathrm{~Hz}$ ) harmonics of $i_{t_{\oplus}}$ are greatly amplified, this happens because these frequencies are close to the filter cutoff frequency $(1200 \mathrm{~Hz})$ and the resonance occurs. However, the 5th and 7 th harmonics are eliminated in the primary side, so this effect is not

\begin{tabular}{|c|c|c|}
\hline Variable & Symbol & Value \\
\hline Output power in each rectifier & $P_{o}$ & $25 \mathrm{~kW}$ \\
\hline Supply rms phase voltage & $V_{s_{\infty}}$ & $108 \mathrm{~V}$ and $118 \mathrm{~V}$ \\
\hline Supply frequency & $f$ & $400 \mathrm{~Hz}$ \\
\hline Voltage ratio & $N$ & 1 \\
\hline Input filter inductor & $L_{i n_{\infty}}$ & $250.6 \mu \mathrm{H}$ \\
\hline Input filter capacitor ( $\Delta$ connection) & $C_{i n_{\infty}}$ & $23.39 \mu \mathrm{F}$ \\
\hline Output filter inductor & $L_{\text {out }}$ & $500 \mu \mathrm{H}$ \\
\hline Output filter capacitor & $C_{\text {out }}$ & $200 \mu \mathrm{F}$ \\
\hline
\end{tabular}
sensed by the source as shown in Fig. 11. It is worth mentioning that this current is flowing through a part of the circuit and, therefore, it should be taken into consideration when dimensioning equipment and components.

Table 3. Plecs simulation parameters - LC filter with variable frequency. 

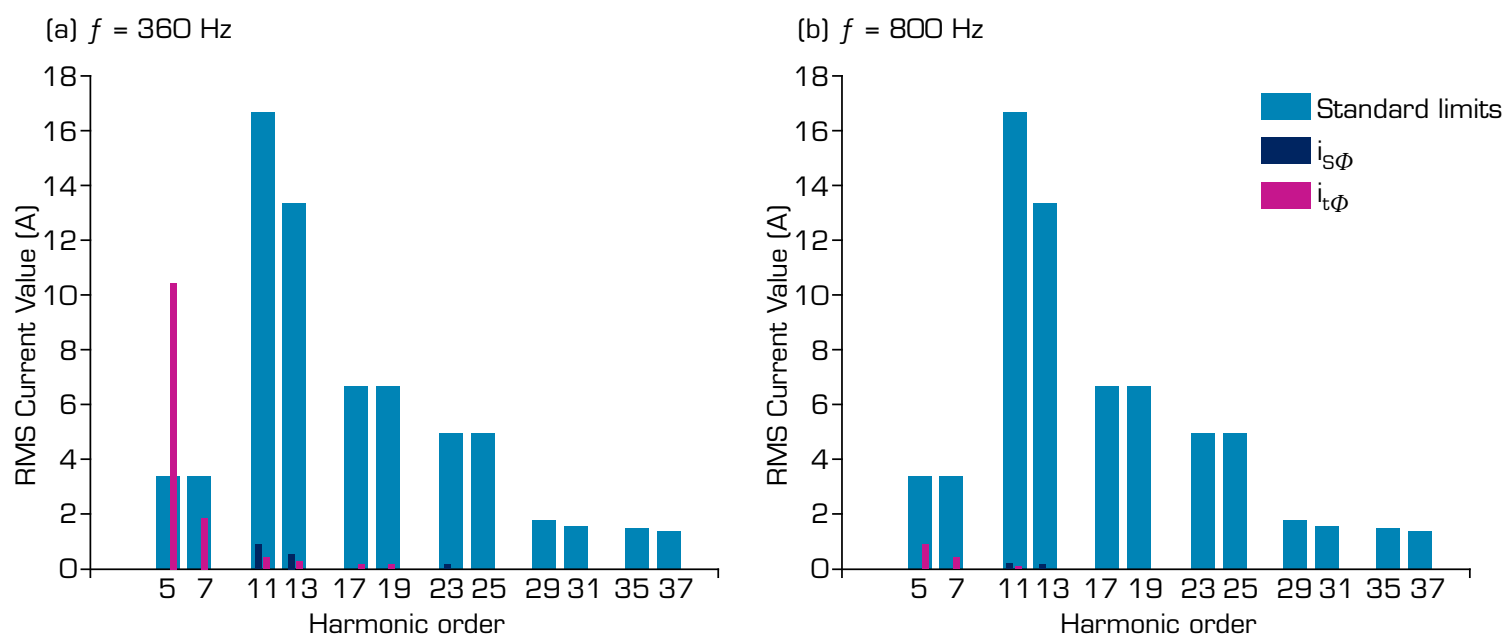

Figure 11. Spectra of source current at the output of the transformer and standard limits with $V_{s \oplus}=118 \mathrm{~V}$.

Table 4 shows the average output voltage for all the circuit situations, such as with the limits of source frequency $(f=360 \mathrm{~Hz}$ and $f=800 \mathrm{~Hz})$ and with the limits of source voltage $\left(V_{s_{\phi}}=108 \mathrm{~V}\right.$ and $\left.V_{s_{\phi}}=118 \mathrm{~V}\right)$. Although the ripple is within the limits established as the standard, the average load voltage exceeds the standard limit $(280 \mathrm{~V})$ for almost all situations.

Table 4. Plecs simulation values of $\bar{V}_{o}$.

\begin{tabular}{ccc}
\hline \multirow{2}{*}{$\boldsymbol{c}$} & \multicolumn{2}{c}{$V_{s_{\Phi}}$} \\
\cline { 2 - 3 } & $108 \mathrm{~V}$ & $118 \mathrm{~V}$ \\
\hline $360 \mathrm{~Hz}$ & $274.4 \mathrm{~V}$ & $301.9 \mathrm{~V}$ \\
\hline $800 \mathrm{~Hz}$ & $390.1 \mathrm{~V}$ & $453.3 \mathrm{~V}$ \\
\hline
\end{tabular}

To better understand the resonance effect, the voltage at the rectifier input is analyzed. Figure 12 shows current and voltage waveforms at the rectifier input, Fig. 13 shows the spectrum of $v_{r_{\Phi}}$ with the maximum value of $V_{s_{\infty}}(118 \mathrm{~V})$, and Table 5 shows the simulation fundamental values of $V_{r_{\phi-1}}$ and $I_{r_{\phi-1}}$, the equivalent impedance seen by the input filter $\left(Z_{1}=V_{r_{\phi-1}} / I_{r_{\phi-1}}\right)$ and the angle between $v_{r_{\phi-1}}$ and $i_{r_{\phi-1}}\left(\varphi_{1}\right)$ for all operation cases.
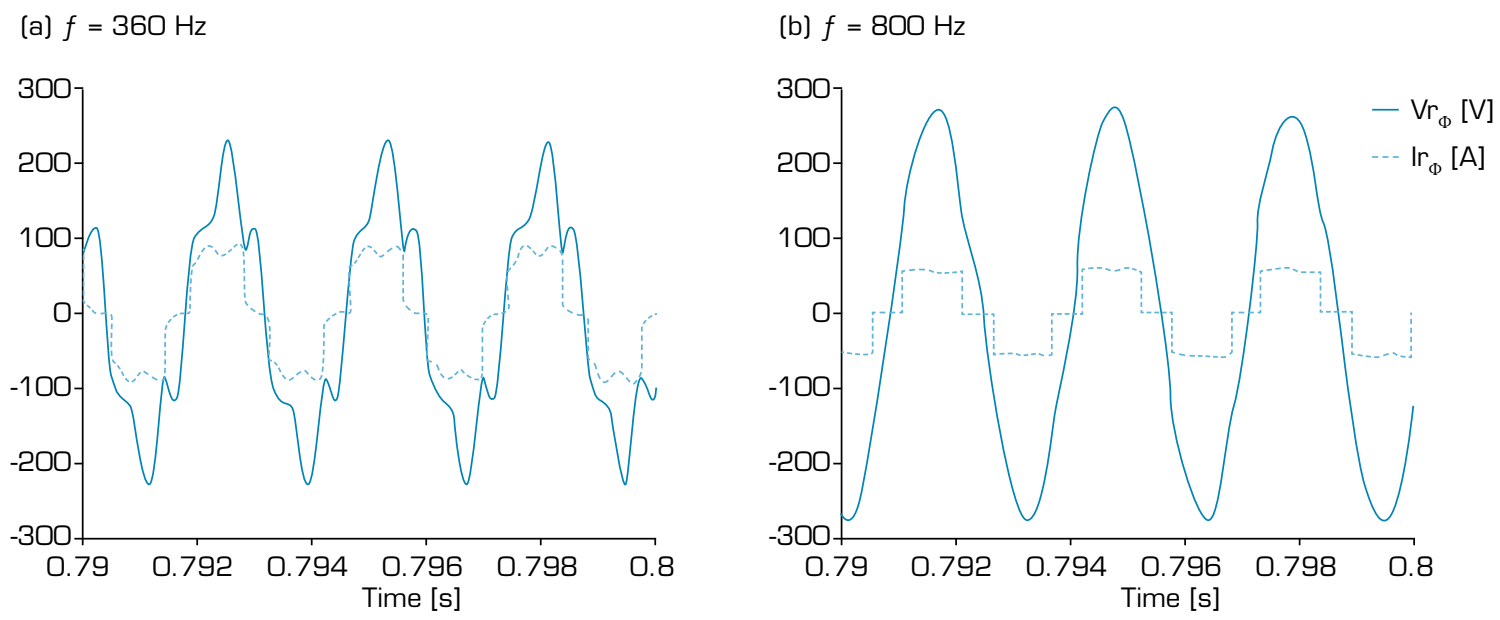

Figure 12. Current and voltage at the input of the rectifier with $V_{s \oplus}=118 \mathrm{~V}$. 


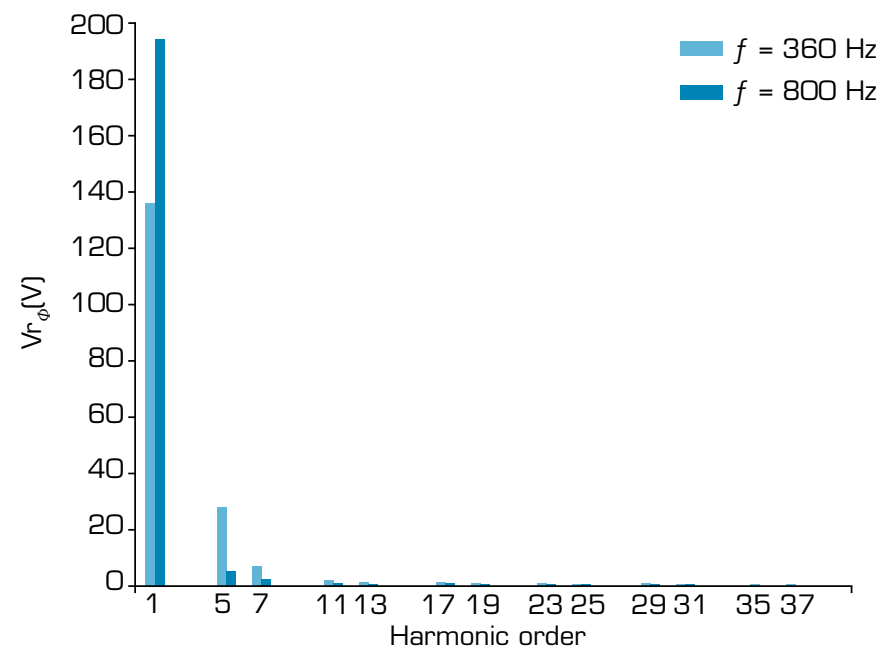

Figure 13. Voltage spectra at the input of the rectifier - RMS value with $V_{s \Phi}=118 \mathrm{~V}$.

Table 5. Simulation values of $V_{r_{\phi-1}}, I_{r_{\oplus-1}}, Z_{1}$ and $\varphi_{1}$ at the fundamental frequency.

\begin{tabular}{|c|c|c|c|c|c|}
\hline & \multicolumn{2}{|c|}{$V_{s_{\Phi}}=108 \mathrm{~V}$} & & \multicolumn{2}{|c|}{$V_{s_{\Phi}}=118 \mathrm{~V}$} \\
\hline & $360 \mathrm{~Hz}$ & $800 \mathrm{~Hz}$ & & $360 \mathrm{~Hz}$ & $800 \mathrm{~Hz}$ \\
\hline$V_{r_{\phi-1}}$ & $123.17 /-20.75^{\circ}$ & $167.35 /-35.41^{\circ}$ & $V_{r_{\infty-1}}$ & $135.065 /-17.19^{\circ}$ & $194.15 /-27.2^{\circ}$ \\
\hline$I_{r_{\phi-1}}$ & $70.45 \angle-4.54^{\circ}$ & $49.96 /-30.72^{\circ}$ & $I_{\Gamma_{\phi-1}}$ & $64.29 /-0.88^{\circ}$ & $42.99 /-23.88^{\circ}$ \\
\hline$Z_{1}$ & $1.68-j 0.49$ & 3.34 -j0.27 & $Z_{1}$ & 2 -j0.59 & $4.51-j 0.26$ \\
\hline$\varphi_{1}$ & $-16.21^{\circ}$ & $-4.69^{\circ}$ & $\varphi_{1}$ & $-16.31^{\circ}$ & $-3.32^{\circ}$ \\
\hline
\end{tabular}

For $360 \mathrm{~Hz}$, current and voltage are more distorted since the resonance frequency $(1200 \mathrm{~Hz})$ is close to the 5 th harmonic $(1800 \mathrm{~Hz})$; this effect can be seen in Fig. 12a. The resonance produces an increase in the 5th harmonic, which is clearly observed in Fig. 13. This distortion also changes the commutation moment of the rectifier and causes a lag between voltage and current at the fundamental $\left(\varphi_{1}\right)$, as detected in Table 5 .

With the circuit operating at $800 \mathrm{~Hz}$, the filter resonance does not strongly interfere with the harmonic components, therefore the harmonic content is lower as can be seen in Fig. 12b and Fig. 13. As a result, the shifting of the commutation point is also smaller (Table 5). However, the fundamental value is amplified by the input filter since the frequency of $800 \mathrm{~Hz}$ is close to the cutoff frequency of the filter $(1200 \mathrm{~Hz})$, which increases the output voltage $\left(\bar{V}_{o}\right)$.

As showed in Table 5, the impedance seen by the input filter is not purely resistive, it also has a reactive part. Applying the model developed to calculate the output voltage (Eq. 20) and using data from Table 5, it is possible to compare the values obtained by simulation and by calculation, as represented in Table 6 . As shown, the results are very close. Thus, by knowing the value of $R_{1}$, it is possible to estimate DC voltage value.

Table 6. Comparison of $V_{o}$ value obtained by calculation and by simulation.

\begin{tabular}{llllll}
\hline & $\boldsymbol{V}_{\boldsymbol{s}_{\oplus}}=108 \mathrm{~V}$ & \multicolumn{2}{c}{$\boldsymbol{V}_{\boldsymbol{s}_{\odot}}=118 \mathrm{~V}$} \\
\hline$(\mathrm{Hz})$ & Calculated & Simulated & $(\mathrm{Hz})$ & Calculated & Simulated \\
\hline 360 & $276.76 \mathrm{~V}$ & $274.37 \mathrm{~V}$ & 360 & $301.97 \mathrm{~V}$ & $301.92 \mathrm{~V}$ \\
\hline 800 & $388.48 \mathrm{~V}$ & $390.1 \mathrm{~V}$ & 800 & $453.47 \mathrm{~V}$ & $453.34 \mathrm{~V}$ \\
\hline
\end{tabular}


Using the mathematical model, it is possible to plot the value of $V_{r_{\odot}}$ as a function of $R_{1}$ and $X_{1}$, like in Fig. 14. As evidenced, the value of $X_{1}$ does not strongly interfere with $V_{r_{\phi}}$. For $800 \mathrm{~Hz}$, there is an increase in $V_{r_{\phi}}$ compared with $360 \mathrm{~Hz}$, when $R_{1}$ increases. The value of the output voltage is directly related to $V_{r}$.

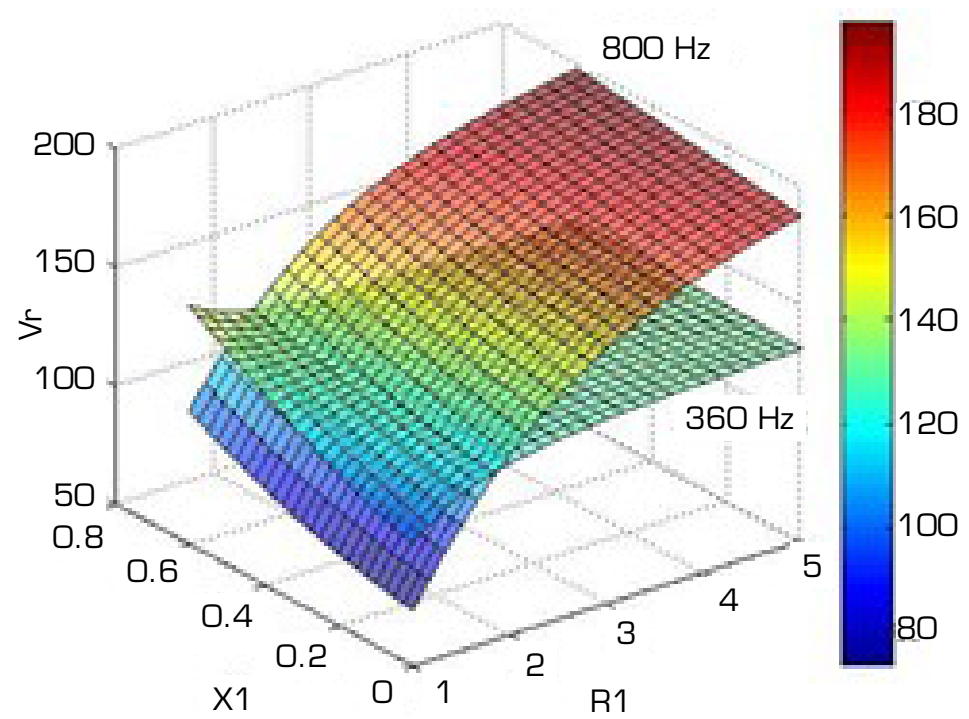

Figure 14. Graph of $V_{r_{\phi}}$ as a function of $R_{1}$ and $X_{1}$.

Using the LC filter, it is possible to increase the value of the input inductor. However, as the circuit operates over a wide range of frequencies, it is not possible to properly tune the filter to not interfere with any harmonic frequency. Therefore, even choosing the cutoff frequency that produces the smallest resonance effect, the output voltage still exceeds the value allowed by the standard.

\section{EXPERIMENTAL RESULTS AND DISCUSSION}

A prototype was assembled with L and LC input filters. The objective of the prototype is to validate the mathematical model and the simulations. For the sake of simplicity, only one arm of the 12-pulse rectifier was tested. With this configuration, the 5 th and 7 th harmonics of the input current are not cancelled, this phenomenon has been widely studied in the literature (Mohan et al. 2003). The tests were done in a small scale for 360 and $800 \mathrm{~Hz}$, and were performed with resistive load and not with constant power load, without loss of generality. Finally, the experimental results were not compared with the standard harmonic limits because of the small size of the prototype.

\section{Prototype with L filter}

Prototype parameters are shown in Table 7. The value of the input inductor was chosen considering the prototype power and according to availability in the laboratory. Output filter values have been chosen to attenuate the harmonics on the DC side. With data from Table 7 and $V_{s \Phi}=118 \mathrm{~V}$, the total power was around $1500 \mathrm{~W}$. This value corresponds to approximately $6 \%$ of the rated power used in the previous analysis. To have an adequate comparison, the circuit was simulated with experimental data (Table 7) on Plecs software. The source voltage used was the 345 - ASX from Pacific Power Source and the diode bridge used was the SKD 62/12 from Semikron. 
Table 7. Prototype parameters with L input filter.

\begin{tabular}{ccc}
\hline Variable & Symbol & Value \\
\hline Supply rms phase voltage & $V_{s_{\phi}}$ & $108-118 \mathrm{~V}$ \\
\hline Supply frequency & $f$ & $360-800 \mathrm{~Hz}$ \\
\hline Input filter inductor & $L_{i n_{\phi}}$ & $134 \mu \mathrm{H}$ \\
\hline Output resistor load & $R_{o}$ & $48 \Omega$ \\
\hline Output filter inductor & $L_{\text {out }}$ & $2.77 \mathrm{mH}$ \\
\hline Output filter capacitor & $C_{\text {out }}$ & $33 \mu \mathrm{F}$ \\
\hline Cutoff frequency of the output filter & $f_{c}$ & $526 \mathrm{~Hz}$ \\
\hline
\end{tabular}

This paper brings only the results for $f=360 \mathrm{~Hz}$ and $V_{s_{\phi}}=118 \mathrm{~V}$, but further results can be found in Vitoi (2018). Figure 15a shows the input current obtained by simulation and by prototype. As indicated, the waveforms are similar. Figure $15 \mathrm{~b}$ shows the simulation and prototype harmonic spectra of $i_{s \phi}$, which, in this case, are the same of $i_{r_{\phi}}$. Simulation and prototype values are quite close, which shows that the model is consistent and accurate. Since the transformer was not used, the 5th and 7th harmonics appear. Figure 16 shows the simulation and experimental rectifier input voltage. The waveforms are very similar, corroborating the model validation. The notch effect is observed due to the input inductance.
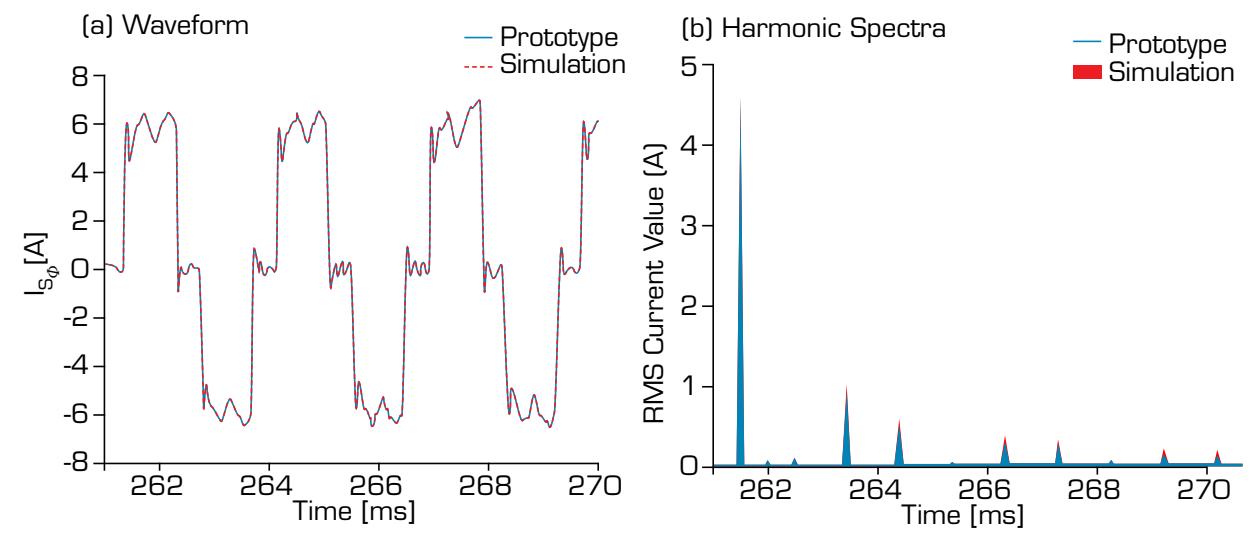

Figure 15. Source current (simulation and prototype values) $V_{s_{\Phi}}=118 \mathrm{~V}$ and $f=360 \mathrm{~Hz}$.

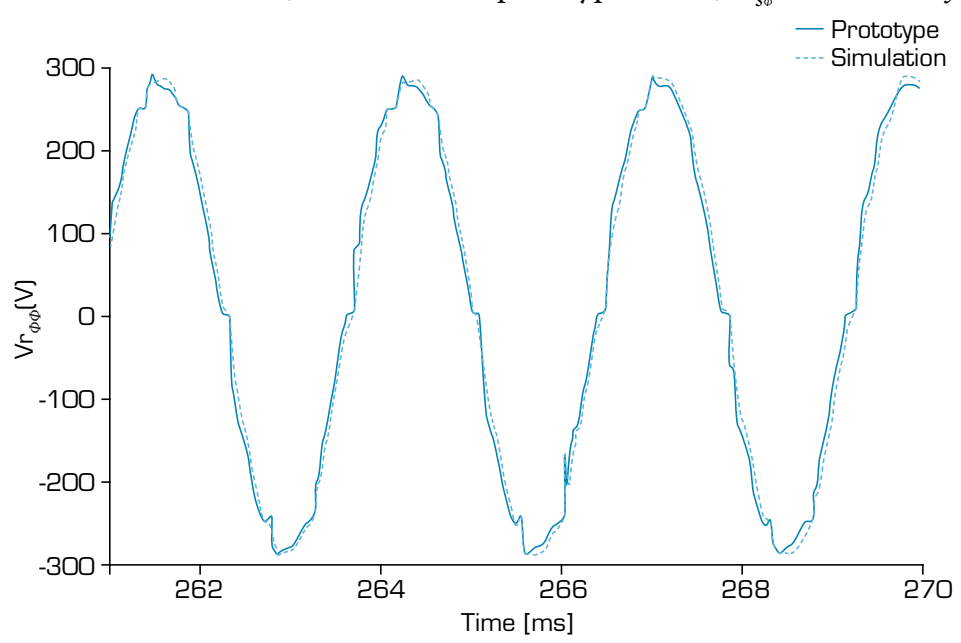

Figure 16. Voltage at the input of the rectifier (simulation and prototype values) $V_{s \Phi}=118 \mathrm{~V}$ and $f=360 \mathrm{~Hz}$. 
As analyzed in the mathematical model, the notch effect causes a decrease in the output voltage. Table 8 shows the comparison between simulated and experimental values of $\bar{V}_{o}$. The difference occurs because the losses and voltage drops present in the system are not included in the mathematical model. As expected, the value of $\bar{V}_{o}$ decreases with increasing frequency, this occurs because the notch effect changes with frequency.

Table 8. Comparison of $\bar{V}_{o}$ value obtained by simulation and at the prototype with L filter.

\begin{tabular}{|c|c|c|c|c|c|}
\hline \multicolumn{3}{|c|}{$V_{s \Phi}=108 \mathrm{~V}$} & \multicolumn{3}{|c|}{$V_{s \Phi}=118 \mathrm{~V}$} \\
\hline$(\mathrm{Hz})$ & Simulation & Prototype & $(\mathrm{Hz})$ & Simulation & Prototype \\
\hline 360 & $251 \mathrm{~V}$ & $242 \mathrm{~V}$ & 360 & $274.3 \mathrm{~V}$ & $264 \mathrm{~V}$ \\
\hline 800 & $249 \mathrm{~V}$ & $236 \mathrm{~V}$ & 800 & 272.3 V & $258 \mathrm{~V}$ \\
\hline
\end{tabular}

\section{Prototype with LC filter}

Table 9 shows the prototype parameters with the LC filter. The input filter was designed according to the methodology described in section B. For comparison with the previous analysis, the same cutoff frequency $(1200 \mathrm{~Hz})$ was chosen. The maximum allowed inductor value was found by Eq. 26 and, for $P_{o}=2.5 \mathrm{~kW}, L_{i n \Phi m a x}$ is around $3.8 \mathrm{mH}$. According to the availability in the laboratory, $L_{i n \phi}=2.9 \mathrm{mH}$ and $C_{i n \infty \phi}=2 \mu \mathrm{F}$ were chosen. Output filter components have been chosen to attenuate the harmonics on the DC side and according to the components available. To have an adequate comparison, the circuit was simulated with experimental data from Table 9 on Plecs software. The source voltage used was the 4500iL AC Power Source - California Instruments, and the diode bridge was the SKKD 46/12 from Semikron.

Table 9. Prototype parameters with LC input filter.

\begin{tabular}{ccc}
\hline Variable & Symbol & Value \\
\hline Supply rms phase voltage & $V_{s_{\oplus}}$ & $108 \mathrm{~V}$ and $118 \mathrm{~V}$ \\
\hline Supply frequency & $f$ & 360 and $800 \mathrm{~Hz}$ \\
\hline Input filter inductor & $L_{i n_{\odot}}$ & $2.9 \mathrm{mH}$ \\
\hline Input filter capacitor ( $\triangle$ connection) & $C_{\text {inoథ }}$ & $2 \mu \mathrm{F}$ \\
\hline Output resistor load & $R_{o}$ & $33.33 \Omega$ \\
\hline Output filter inductor & $L_{\text {out }}$ & $1 \mathrm{mH}$ \\
\hline Output filter capacitor & $C_{\text {out }}$ & $235 \mu \mathrm{F}$ \\
\hline
\end{tabular}

Figure 17 shows the source current in the prototype and in the simulation. As shown, the waveforms are rather similar. Figure 18 shows the simulation and prototype harmonic spectra of $i_{s_{\varphi}}$ and the harmonics values from the simulation and prototype are very close.
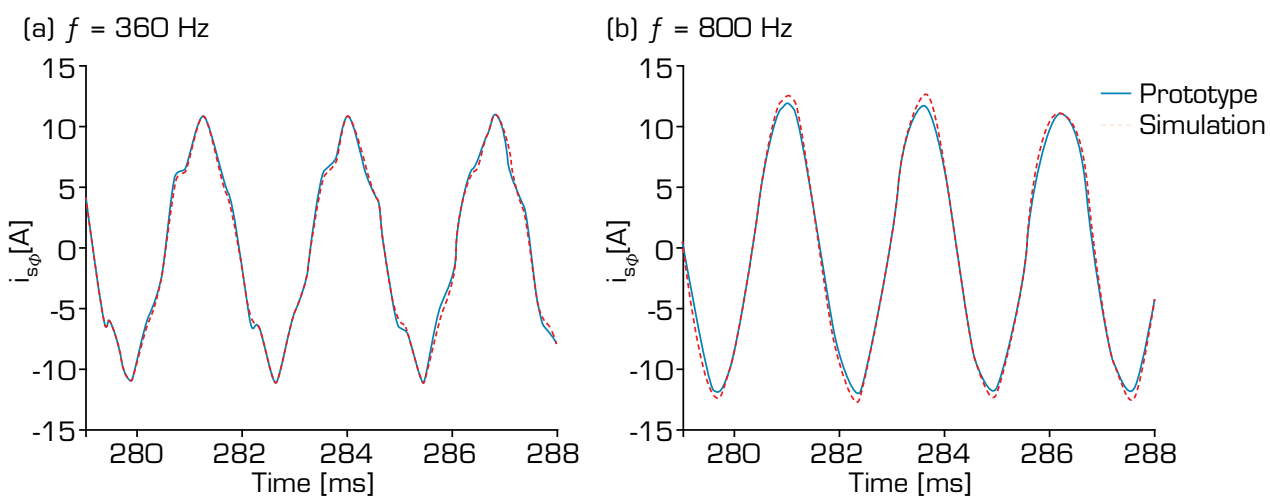

Figure 17. Source current (simulation and prototype values) $V_{s \Phi}=118 \mathrm{~V}$. 

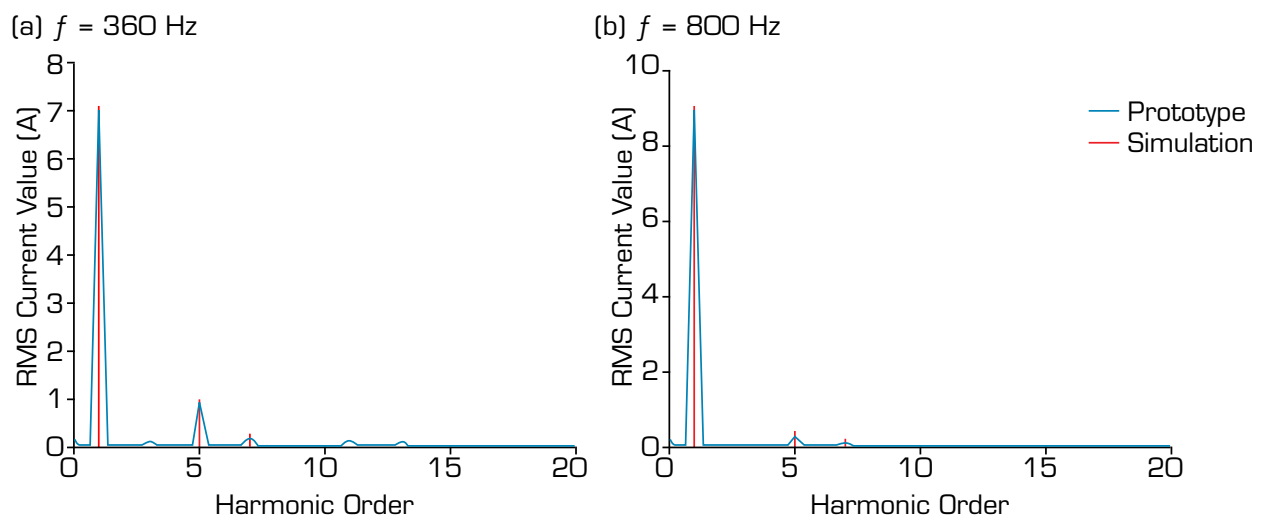

Figure 18. Harmonic spectra of the source current (simulation and prototype values) $V_{s \oplus}=118 \mathrm{~V}$.

Table 10 shows the comparison of $\bar{V}_{o}$. The differences are due to the real conditions that are not considered in the simulation, such as voltage drop in the diodes and components resistances. As expected, the output voltage increases under higher frequencies, with $V_{s \Phi}=118 \mathrm{~V}$, for $360 \mathrm{~Hz}$, the relation $\bar{V}_{o} / V_{s_{\oplus}}=2.02$, and for $800 \mathrm{~Hz}, \overline{V_{o}} / V_{s \Phi}=2.54$. This effect is due to resonance that was discussed in Section B.

Table 10. Comparison of $\overline{V_{o}}$ value obtained by simulation and in the prototype.

\begin{tabular}{llllll}
\hline & $\boldsymbol{V}_{\boldsymbol{s}_{\odot}}=108 \mathrm{~V}$ & & \multicolumn{2}{c}{$\boldsymbol{V}_{\boldsymbol{s}_{\odot}}=118 \mathrm{~V}$} \\
\hline$(\mathrm{Hz})$ & Simulation & Prototype & $(\mathrm{Hz})$ & Simulation & Prototype \\
\hline 360 & $263.8 \mathrm{~V}$ & $258.4 \mathrm{~V}$ & 360 & $288.1 \mathrm{~V}$ & $283.01 \mathrm{~V}$ \\
\hline 800 & $280.2 \mathrm{~V}$ & $273.4 \mathrm{~V}$ & 800 & $306.2 \mathrm{~V}$ & $299.5 \mathrm{~V}$ \\
\hline
\end{tabular}

To analyze the increase in $\bar{V}_{o}$, the input voltage of the rectifier must be evaluated. Figure 19 shows $v_{r}$, obtained by prototype and by simulation with $V_{s \omega}=118 \mathrm{~V}$. The waveforms are similar, whereas the peak values are attenuated in the prototype. The waveforms at $360 \mathrm{~Hz}$ exhibit greater distortion since the 5 th and 7 th harmonics are close to the filter resonance frequency $(1200 \mathrm{~Hz})$, so they are amplified. Figure 20 shows the harmonic spectra of $v_{r_{\infty}}$ obtained by the prototype for $360 \mathrm{~Hz}$ and $800 \mathrm{~Hz}$. As evidenced, at $800 \mathrm{~Hz}$, the fundamental value is amplified since it is close to the filter resonance value $(1200 \mathrm{~Hz})$, which causes an increase in the output voltage $\left(V_{o}\right)$. For $360 \mathrm{~Hz}$, the 5th harmonic is amplified, once it is close to $1200 \mathrm{~Hz}$, making the voltage waveform more distorted.

(a) $f=360 \mathrm{~Hz}$

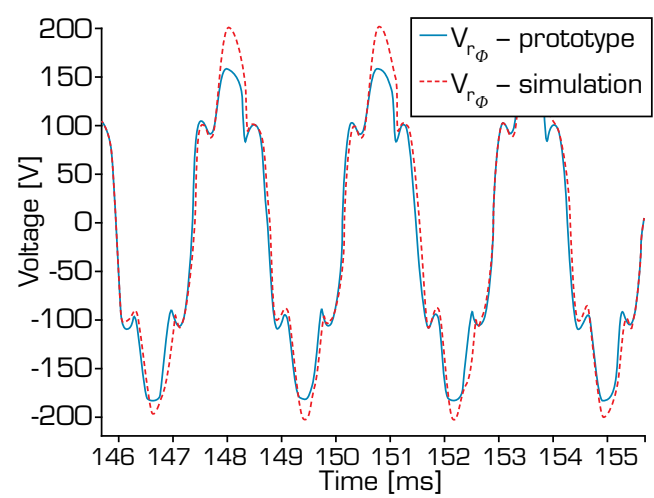

(b) $f=800 \mathrm{~Hz}$

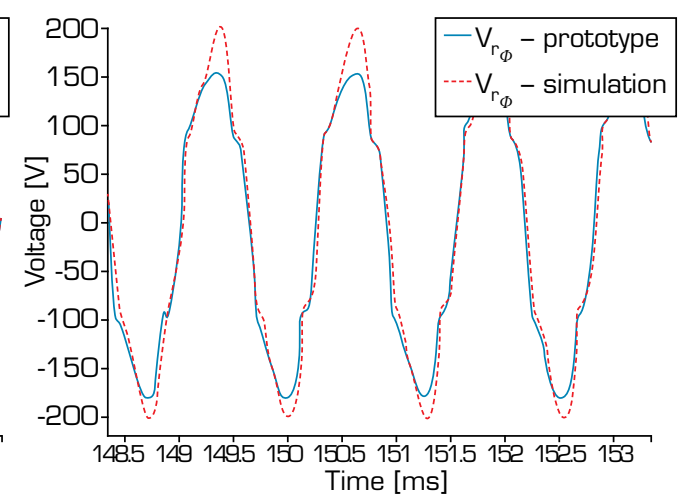

Figure 19. Voltage at the input of the rectifier (simulation and prototype values) $V_{s_{\oplus}}=118 \mathrm{~V}$. 

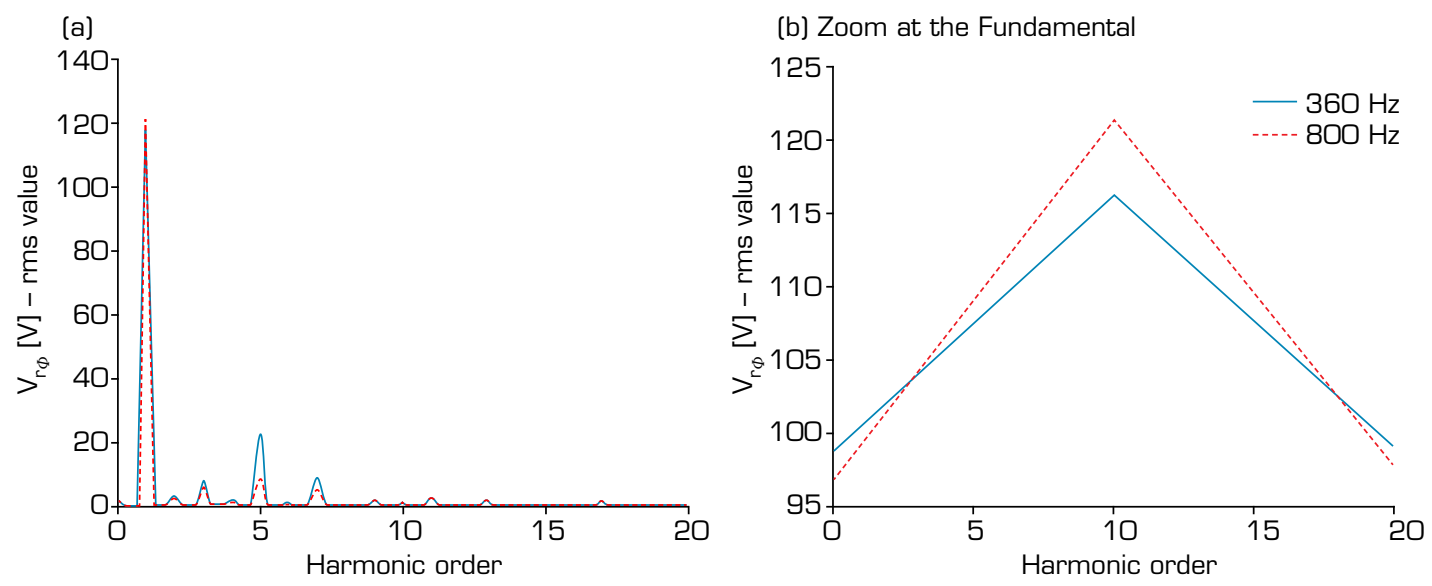

Figure 20. Harmonic spectra of the input voltage of the rectifier (prototype values) $V_{s \Phi}=118 \mathrm{~V}$.

\section{CONCLUSION}

This work analyzed the feasibility of a 12-pulse passive rectifier for aeronautical systems operating with variable frequency $(360-800 \mathrm{~Hz})$ and with symmetrical DC voltage $( \pm 270 \mathrm{~V})$. The evaluations were done with two input filters: L and LC. In both cases, mathematical models were proposed and then simulations and prototypes were developed. All results are in agreement, which shows that the mathematical models are accurate and their use is valid. The proposed mathematical models can also be applied to 6-pulse diode rectifiers for any frequency range.

For the passive rectifier based on the $\mathrm{L}$ filter, it is possible to find an inductance value that satisfies the aeronautical standard constraints, but this value is too small when compared with the typical circuit values (e.g., inductances of transformers, wires and generator). For that reason, this solution becomes impractical.

For the 12-pulse passive rectifier based on the LC filter, it is possible to increase the inductance value and still meet the harmonic limits of the input current. However, the allowed range for the filter cutoff frequency is very narrow and the resonance phenomenon increases the output voltage. Therefore, it is not possible to meet the requirements of aeronautical standards. The use of high order filter would increase the complexity of the system, making it difficult to be applied.

Therefore, it is concluded that, although the 12-pulse passive rectifier is a common solution for the aeronautical system operation in constant frequency, it is not a viable solution when operating under variable frequency. For this reason, active converters appear as the best solution.

\section{AUTHORS' CONTRIBUTION}

Conceptualization: Vitoi LA; Pomilio JA; Supervision: Pomilio JA; Data Curation: Vitoi LA; Formal Analysis: Vitoi LA; Investigation: Vitoi LA; Methodology: Vitoi LA; Software: Vitoi LA; Validation: Vitoi LA; Visualization: Vitoi LA; Funding Acquisition: Pomilio JA; Project Administration: Pomilio JA; Resources: Brandão DI; Writing - Original Draft Preparation: Vitoi LA; Pomilio JA; Writing - Review \& Edition: Vitoi LA; Pomilio JA; Brandão DI.

\section{DATA AVAILABILITY STATEMENT}

Not applicable. 


\section{FUNDING}

Fundação de Amparo à Pesquisa do Estado de São Paulo

http://dx.doi.org/10.13039/501100001807

Grant No: 2017/05565-7.

Conselho Nacional de Desenvolvimento Científico e Tecnológico

http://dx.doi.org/10.13039/501100003593

Grant No: 401216/2016-0.

Coordenação de Aperfeiçoamento de Pessoal de Nível Superior

http://dx.doi.org/10.13039/501100002322

Finance Code 001.

\section{ACKNOWLEDGMENTS}

Not applicable.

\section{REFERENCES}

Baghramian A, Cross A, Forsyth A (2011) Interactions within heterogeneous systems of uncontrolled rectifiers for aircraft electrical power systems. IET Electr Syst Transp 1(1):49-60. https://doi.org/10.1049/iet-est.2010.0002

Buticchi G, Costa L, Liserre M (2017) Improving System efficiency for the more electric aircraft: A Look at DCV/ DC converters for the avionic onboard DC microgrid. IEEE Ind Electron Mag 11(3):26-36. https://doi.org/10.1109/ MIE.2017.2723911

Cao W, Mecrow BC, Atkinson GJ, Bennett JW, Atkinson DJ (2012) Overview of electric motor technologies used for more electric aircraft (MEA). IEEE Trans Ind Electron 59(9):3523-3531. https://doi.org/10.1109/TIE.2011.2165453

Chen J, Zhang X, Wen C (2016) Harmonics attenuation and power factor correction of a more electric aircraft power grid using active power filter. IEEE Trans Ind Electron 63(12):7310-7319. https://doi.org/10.1109/TIE.2016.2590990

Chivite-Zabalza FJ, Forsyth AJ (2005) A simple, passive 24-pulse AC-DC converter with inherent load balancing using harmonic voltage injection. Paper presented 2005 IEEE 36th Power Electronics Specialists Conference. IEEE; Recife, Pernambuco, Brazil. https://doi.org/10.1109/PESC.2005.1581605

Cross A, Baghramian A, Forsyth A (2009) Approximate, average, dynamic models of uncontrolled rectifiers for aircraft applications. IET Power Electron 2(4):398-409. https://doi.org/10.1049/iet-pel.2007.0021

Emadi K, Ehsani M (2000) Aircraft power systems: technology, state of the art, and future trends. IEEE Aerosp Electron Syst Mag 15(1):28-32. https://doi.org/10.1109/62.821660

Gong G, Drofenik U, Kolar JW (2003) 12-pulse rectifier for more electric aircraft applications. Paper presented IEEE International Conference on Industrial Technology, 2003. IEEE; Maribor, Slovenia. https://doi.org/10.1109/ ICIT.2003.1290816 
Gong G, Heldwein ML, Drofenik U, Mino K, Kolar JW (2004) Comparative evaluation of three-phase high power factor AC-DC converter concepts for application in future more electric aircrafts. Paper presented Nineteenth Annual IEEE Applied Power Electronics Conference and Exposition, 2004. APEC '04. IEEE; Anaheim, California, USA. https://doi.org/10.1109/APEC.2004.1295968

Gong G, Heldwein ML, Drofenik U, Minibock J, Mino K, Kolar JW (2005) Comparative evaluation of three-phase highpower-factor AC-DC converter concepts for application in future More Electric Aircraft. IEEE Trans Ind Electron 52(3):727737. https://doi.org/10.1109/TIE.2005.843957

Hartmann M, Miniboeck J, Ertl H, Kolar JW (2012) A three-phase delta switch rectifier for use in modern aircraft. IEEE Trans Ind Electron 59(9):3635-3647. https://doi.org/10.1109/TIE.2011.2158770

Jia Y, Rajashekara K (2017a) An induction generator-based AC/DC hybrid electric power generation system for more electric aircraft. IEEE Trans Ind Appl 53(3):2485-2494. https://doi.org/10.1109/TIA.2017.2650862

Jia Y, Rajashekara K (2017b) Induction machine for more electric aircraft: Enabling new electrical power system architectures. IEEE Electrific Mag 5(4):25-37. https://doi.org/10.1109/MELE.2017.2755267

Jiang L, Chen Q, Mao L, Ren X, Ruan X (2012) Asymmetrical operation analysis of multi-pulse ATRU. Paper presented Proceedings of 7 th International Power Electronics and Motion Control Conference. IEEE; Harbin, China. https://doi. org/10.1109/IPEMC.2012.6258824

Mino K, Gong G, Kolar JW (2005) Novel hybrid 12-pulse boost-type rectifier with controlled output voltage. IEEE Trans Aerosp Electron Syst 41(3):1008-1018. https://doi.org/10.1109/TAES.2005.1541445

Mohan N, Undeland TM, Robbins WP (2003) Power Electronics. Converters, Applications and Design. Hoboken: John Wiley and Sons.

Rashid MH (2009) Power Electronics: Circuits, Devices, and Applications. London: Pearson.

Rosero JA, Ortega JA, Aldabas E, Romeral L (2007) Moving towards a more electric aircraft. IEEE Aerosp Electron Syst Mag 22(3):3-9. https://doi.org/10.1109/MAES.2007.340500

Sarlioglu B, Morris CT (2015) More electric aircraft: review, challenges, and opportunities for commercial transport aircraft. IEEE Trans Transp Electrification 1(1):54-64. https://doi.org/10.1109/TTE.2015.2426499

Taha M (2018) 12-Pulse Active Rectifier for More Electric Aircraft Applications. In: Volkov K, editors. Flight Physics: Models, Techniques and Technologies. London: IntechOpen. p. 211-228. https://doi.org/10.5772/intechopen.70882

USA (2007) RTCA, Inc. Document RTCA/DO-160E - Environmental conditions and test procedures for airborne equipment (Advisory Circular). U.S. Department of Transportation, Federal Aviation Administration.

USA (2008) Aircraft electric power characteristics (MIL-STD-704F). Department of Defense Interface Standard.

Vitoi LA (2018) Analysis of 12 and 24-pulse diode rectifiers operating in aircraft systems with constant and variable frequency (Master's Thesis). Campinas: Universidade Estadual de Campinas. In Portuguese.

Vitoi LA, Pomilio JA, Brandao DI (2017a) Analysis of 12-pulse diode rectifier operating in aircraft systems with constant frequency. Paper presented 2017 Brazilian Power Electronics Conference (COBEP). IEEE; Juiz de Fora, Minas Gerais, Brazil. https://doi.org/10.1109/COBEP.2017.8257274

Vitoi LA, Pomilio JA, Brandao DI (2017b) Analysis of 12-pulse diode rectifier operating in aircraft systems with variable frequency. Paper presented 2017 IEEE Southern Power Electronics Conference (SPEC). IEEE; Puerto Varas, Chile. https:// doi.org/10.1109/SPEC.2017.8333591 
Wheeler P, Bozhko S (2014) The more electric aircraft: technology and challenges. IEEE Electrific Mag 2(4):6-12. https://doi. org/10.1109/MELE.2014.2360720

Xu K, Xie N, Wang C, Shi X (2017) Modeling and simulation of variable speed variable frequency electrical power system in more electric aircraft. Open Electr Electron Eng J 11:87-98.

Yin S, Tseng KJ, Simanjorang R, Liu Y, and Pou J (2017) A 50-kW High-frequency and high-efficiency SiC voltage source inverter for more electric aircraft. IEEE Trans Ind Electron 64(11):9124-9134. https://doi.org/10.1109/TIE.2017.2696490 